\title{
Lysyl oxidase is associated with the epithelial-mesenchymal transition of gastric cancer cells in hypoxia
}

\author{
Hiroaki Kasashima ${ }^{1} \cdot$ Masakazu Yashiro $^{1,2} \cdot$ Haruhito Kinoshita $^{1}$. \\ Tatsunari Fukuoka $^{1}$ - Tamami Morisaki ${ }^{1}$ - Go Masuda ${ }^{1} \cdot$ Katsunobu Sakurai $^{1}$ • \\ Naoshi Kubo ${ }^{1} \cdot$ Masaichi Ohira $^{1} \cdot$ Kosei Hirakawa ${ }^{1}$
}

Received: 8 January 2015 / Accepted: 6 June 2015/Published online: 23 June 2015

(c) The International Gastric Cancer Association and The Japanese Gastric Cancer Association 2015

\begin{abstract}
Purpose It has been reported that lysyl oxidase (LOX) is a hypoxia-responsive factor and is associated with the malignant progression of carcinoma. The aim of this study was to clarify the relationship between the epithelialmesenchymal transition (EMT) and LOX in gastric cancer cells under hypoxia.

Methods Two gastric cancer cell lines, OCUM-2MD3 and OCUM-12, were used in an in vitro study. The effect of $L O X$ small interfering RNA (siRNA) on the EMT and motility of gastric cancer cells under hypoxic condition was analyzed by reverse transcription PCR, Western blot, a wound-healing assay, and an invasion assay. Correlations between LOX expression and the clinicopathological features of 544 patients with gastric carcinoma were examined immunohistochemically.

Results Hypoxic conditions increased the number of polygonal or spindle-shaped cells resulting from EMT in gastric cancer cells. The EMT of cancer cells induced by hypoxia was inhibited by treatment with $L O X$ siRNA. The number of migrating and invading gastric cancer cells in hypoxia was significantly decreased by $L O X$ knockdown. $L O X$ siRNA significantly increased the E-cadherin level
\end{abstract}

Electronic supplementary material The online version of this article (doi:10.1007/s10120-015-0510-3) contains supplementary material, which is available to authorized users.

Masakazu Yashiro

m9312510@med.osaka-cu.ac.jp

1 Department of Surgical Oncology, Osaka City University Graduate School of Medicine, 1-4-3 Asahi-machi, Abeno-ku, Osaka 545-8585, Japan

2 Oncology Institute of Geriatrics and Medical Science, Osaka City University Graduate School of Medicine, Osaka, Japan and decreased the vimentin level of gastric cancer cells. LOX expression was significantly associated with invasion depth, tumor differentiation, lymph node metastasis, lymphatic invasion, venous invasion, and peritoneal metastasis. Multivariable analysis revealed that LOX was an independent parameter for overall survival.

Conclusion LOX affects the EMT of gastric cancer cells in hypoxic conditions. LOX expression is a useful prognostic factor for patients with gastric cancer.

Keywords Gastric cancer - Lysyl oxidase · Epithelialmesenchymal transition

\section{Introduction}

Hypoxic environments are randomly scattered throughout carcinomas owing to the heterogeneous nature of angiogenesis [1]. Although hypoxia is cytotoxic to both cancer cells and normal cells, some types of cancer cells acquire characteristics that allow them to survive and progress in a hypoxic environment [2]. Hypoxia is considered to be associated with aggressive tumor phenotypes of gastric carcinomas [3], including the ability to metastasize [4]. Hypoxia is clinically associated with metastasis and poor patient outcome, although the underlying processes remain unclear [5]. It has been reported that hypoxia promotes tumor epithelial-mesenchymal transition (EMT), invasion, and metastasis, largely mediated by the targets of hypoxiainducible factors (HIFs) [6]. HIF-1 $\alpha$, a subunit of HIF-1, mediated hypoxia-induced tumor cell migration and invasion through Notch signaling in colon and ovarian cancer cells [7]. It is thus important for the development of cancer treatments to clarify the mechanism responsible for the aggressive tumor phenotypes induced by hypoxia. 
Lysyl oxidase (LOX) is synthesized as a $50-\mathrm{kDa}$ proenzyme (pro-LOX) that is secreted and then cleaved in the extracellular space by bone morphogenetic protein 1 to form a $30-\mathrm{kDa}$, mature, active enzyme and an $18-\mathrm{kDa}$ propeptide (LOX-PP) [8, 9]. LOX and its family members, LOX-like 1-4, oxidize lysine residues in collagens and elastin [10], which results in covalent cross-linking and stabilization of these extracellular matrix structural components, conferring on collagen and elastic fibers much of their tensile strength [11]. LOX families are involved in a variety of pathological processes related to connective tissue $[12,13]$, including cancer progression and metastasis $[11,14]$. Involvement of the LOX family is widely accepted as a poor prognostic factor for patients with cancer [15-20]. By contrast, Kaneda et al. [21] reported that $L O X$ is a tumor suppressor gene inactivated by heavy methylation of the $5^{\prime}$ untranslated region and loss of heterozygosity in gastric cancers, and several studies have reported that LOX-PP has tumor suppressor activity [2224]. Both downregulation and upregulation of LOX in tumor tissues and cancer cell lines have been described [25-28], suggesting a paradoxical role for $L O X$ as a tumor suppressor $[21,29]$ as well as a metastasis promoter gene $[30,31]$.

In addition, Erler et al. [31] have reported that LOX is related to hypoxia-induced metastasis in breast cancer. Several studies have reported associations between hypoxia and LOX in other types of cancer [25, 32], and HIF-1 is a critical regulator of breast cancer metastatic niche formation through induction of multiple members of the LOX family, including LOX, LOX-like 2, and LOX-like 4 [30]. In addition, hypoxia-induced LOX modulates tumor metastasis through activation of $\beta_{1}$ integrin signaling [3335].

We previously reported that hypoxia stimulates the EMT. resulting in a highly invasive form of gastric cancer in vitro and that transforming growth factor $\beta$ (TGF $\beta$ ) is one of the factors regulating EMT under hypoxia [36, 37]. However, the mechanisms of EMT under hypoxic conditions have not been fully revealed, and we speculated LOX is associated with gastric cancer progression in a hypoxic environment.

The aim of this study was to identify the relationship between hypoxic EMT and LOX in gastric cancer.

\section{Materials and methods}

\section{Cell lines}

We used two gastric cancer cell lines, OCUM-2MD3 [38] and OCUM-12 [39], derived from diffuse-type gastric carcinomas. The culture medium consisted of Dulbecco's modified Eagle's medium (DMEM; Wako, Osaka, Japan) with the addition of $10 \%$ fetal bovine serum (FBS; Nichirei., Tokyo, Japan), $100 \mathrm{IU} / \mathrm{ml}$ penicillin (Wako), $100 \mathrm{mg} / \mathrm{ml}$ streptomycin (Wako), and $0.5 \mathrm{mM}$ sodium pyruvate (Wako). Cells were cultured at $37{ }^{\circ} \mathrm{C}$ in $21 \% \mathrm{O}_{2}$ (normoxia) or $1 \% \mathrm{O}_{2}$ (hypoxia) in a modular incubator chamber (Hirasawa, Tokyo, Japan) with $5 \% \mathrm{CO}_{2}$ and balanced with $\mathrm{N}_{2}$ gas.

\section{Preparation of conditioned medium}

We prepared conditioned medium from OCUM-12 and OCUM-2MD3 cells, which were transfected with $L O X$ small interfering RNA (siRNA; siLOX\#1 and siLOX\#2) or negative siRNA. To obtain conditioned medium, gastric cancer cells were washed with phosphate-buffered saline and then incubated for an additional $48 \mathrm{~h}$ in DMEM without FBS. Next, conditioned medium was collected from each dish. The supernatant was stored as conditioned medium at $-20{ }^{\circ} \mathrm{C}$ until use.

\section{Design of siRNA}

The siRNA and nontargeting siRNA (negative siRNA) were purchased from Ambion (Life Technologies, Carlsbad, CA ,USA): HIF1A (which encodes HIF-1 $\alpha$ ) siRNA (siHIF-1 $\alpha$; ID s6539), siLOX\#1 (ID s8254), and siLOX\#2 (ID s8255). OCUM-2MD3 and OCUM-12 cells were prepared at 50-60\% confluence in six-well dishes. The transfection mixture was prepared by addition of $150 \mu \mathrm{L}$ of Opti-MEM including $9 \mu \mathrm{L}$ of Lipofectamine RNA iMAX reagent (Life Technologies) to $150 \mu \mathrm{L}$ of Opti-MEM including 90 pmol of siRNA, followed by incubation for $5 \mathrm{~min}$ at room temperature. Finally, the transfection mixture was added to a six-well dish containing $1.7 \mathrm{~mL}$ of DMEM with $2 \%$ FBS. Twenty-four hours after transfection, quantitative reverse transcription (RT) polymerase chain reaction (PCR) and Western blot were done and conditioned medium was prepared.

\section{Quantitative real-time RT-PCR}

Real-time PCR was performed with an ABI Prism 7000 instrument (Applied Biosystems, Foster City, CA, USA). Total cellular RNA was extracted from cell lines with Trizol (Life Technologies). Relevant complementary DNA was amplified by PCR with Taq DNA polymerase (Nippon Gene, Tokyo, Japan) in a thermal cycler. The primer set for LOX (accession number NM_002317) was 5'-TGCCTCA GGCTGCACAATTTCACCGTA-3' (probe), 5'-TCGCTA CACAGGACATCATGC- $3^{\prime}$ (forward primer), and $5^{\prime}$ CAATGGATAAATCAGTGCCTGGTG-3' (reverse primer), and that for VIM (accession number NM_003380; 
which encodes vimentin) was 5'-ACAGGATGTTGA CAATGCGTCTCTGGCA-3' (probe), 5'-AGGAGGAGAT GCTTCAGAGAGA- $3^{\prime}$ (forward primer), and (5'TGACCTTGAACGCAAAGTGGA- $3^{\prime}$ (reverse); they were customized sets from Sigma-Aldrich (St. Louis, MO, USA). HIFlA (assay ID Hs01565584) and CDHl (assay ID Hs01023894; which encodes E-cadherin) were from Applied Biosystems. As an internal control, glyceraldehyde 3-phosphate dehydrogenase (GAPDH) (accession number NM_002046, NM_001256799) - 5'-CCCCTGCAAATGAGCCCCAGCCTTC-3' (probe), 5'-CCATCTTCCAGGAGCGAGATC-3' (forward primer), and $5^{\prime}$ GGCAGAGATGATGACCCTTTTG-3' (reverse primer)was obtained customized from Sigma-Aldrich.

RT-PCR was performed at $95{ }^{\circ} \mathrm{C}$ for $15 \mathrm{~s}$ and $60{ }^{\circ} \mathrm{C}$ for $60 \mathrm{~s}$ for 40 cycles with the ABI Prism 7000 instrument. The threshold cycle values were used for calculation of the relative expression ratios between control and treated cells. All quantitative PCRs were done in triplicate.

\section{Morphological changes}

Cancer cells were cultured under normoxic or hypoxic conditions with negative siRNA, siLOX\#1, or siLOX\#2 for $24 \mathrm{~h}$, and cell morphology was observed microscopically. EMT was determined when polygonal or spindle-shaped cancer cells were found by phase-contrast microscopy.

\section{Western blot analysis}

Expression levels of LOX, E-cadherin, and vimentin were examined as follows. Cell lysates or condition media were collected after different treatments. Cancer cells were incubated under normoxic conditions without treatment or under hypoxic conditions with negative siRNA, siLOX\#1, siLOX\#2, or siHIF- $1 \alpha$ for $48 \mathrm{~h}$. After the protein concentration of each sample had been adjusted, electrophoresis was done using $10 \%$ tris(hydroxymethyl)aminomethaneglycine gels (Life Technologies). The protein bands obtained were transferred to an Immobilon-P transfer membrane (Amersham, Aylesbury, UK). Then, the membrane was placed in a solution of phosphate-buffered saline and Tween 20 containing anti-LOX antibody (Novus Biologicals, Littleton, CO, USA), anti-E-cadherin antibody (Cell Signaling, Danvers, MA, USA), and anti-vimentin antibody (Abcam, Cambridge, MA, USA) and allowed to react at room temperature for $2 \mathrm{~h}$. The levels of specific proteins in each lysate were detected by enhanced chemiluminescence with ECL Plus (Amersham) followed by autoradiography.

\section{Wound-healing assay}

Gastric cancer cells were cultured in 96-well plates (Essen ImageLock; Essen Instruments, Birmingham, UK). After the cells had reached semiconfluence, a wound was created in the cell monolayer with a 96-well WoundMaker (Essen Bioscience, Ann Arbor, MI, USA). Cancer cells were cultured in DMEM with $2 \%$ FBS. Scratched fields were pictured every $3 \mathrm{~h}$, and were monitored with an IncuCyte live-cell imaging system and software (Essen Instruments). The degree of cell migrations was analyzed $12 \mathrm{~h}$ after wound treatment as a percentage of wound confluence. The mean of four fields was calculated as the sample value.

\section{Invasion assay}

The in vitro invasiveness was measured by a two-chamber Matrigel invasion assay involving chemotaxis cell chambers (Millipore, Billerica, MA, USA) with a $12-\mu \mathrm{m}$ pore membrane filter coated with $50 \mu \mathrm{g}$ of Matrigel (upper chamber) in a 24 -well culture plate (lower chamber), as previously reported [40]. Gastric cancer cells $\left(2 \times 10^{4}\right.$ cells per $200 \mu \mathrm{L}$ per chamber) were seeded in the upper chamber, and $500 \mu \mathrm{L}$ of DMEM with $2 \%$ FBS was added to the lower chamber. After incubation in $20 \% \mathrm{O}_{2}$ (normoxia) or $1 \% \mathrm{O}_{2}$ (hypoxia) for $22 \mathrm{~h}$, cancer cells that invaded the lower surface of the membrane through a filter were stained by Diff-Quik (Sysmex, Kobe, Japan), and were manually counted under a microscope at $\times 200$ magnification. Six randomly chosen fields were counted for each assay. The mean of six fields was calculated as the sample value.

\section{Clinical materials}

A total of 544 patients who had undergone a resection of the primary tumor and were confirmed histologically to have sporadic gastric cancer were enrolled in this study. Of the 544 patients with resectable cancer, 442 underwent a potentially curative $\mathrm{R} 0$ resection; the remaining 102 patients were treated with a palliative resection. None of the patients had undergone preoperative radiation therapy or chemotherapy. The pathological diagnoses and classifications were made according to the Union for International Cancer Control TNM classification of malignant tumors. The study protocol conformed to the ethical guidelines of the Declaration of Helsinki. This study was approved by the Osaka City University Ethics Committee. Written informed consent was obtained from all patients. 


\section{Immunohistochemical determination of LOX}

An anti-LOX antibody (Abcam, Cambridge, MA, USA) and an anti-carbonic anhydrase 9 (CA9) antibody (1: 1000; NB 100-417, Novus Biologicals, Littleton, CO, USA) were used. The methods used for the immunohistochemical determination are described in the kit manufacturer's instructions, as previously reported [14]. LOX expression was evaluated by the intensity of staining and the percentage of stained cancer cells at the invading tumor front: intensity was given a score ranging from 0 to $2(0=$ no intensity, $1=$ weak to moderate intensity, $2=$ intense intensity), and the percentage of immunopositive cells was given a score ranging from 0 to $4(0=0 \%, 1=1-30 \%$, $2=31-60 \%, 3=61-80 \%, 4=81-100 \%)$. The two scores were multiplied to obtain the final result, ranging from 0 to 8 . Expression was considered positive when the scores was 5 or more and was considered negative when the score was 4 or less. CA9 expression was evaluated as previously reported [41]. Evaluation was done by two double-blinded independent observers who were unaware of the clinical data and outcome. When there was a discrepant evaluation between the two independent observers, the evaluation was rechecked and discussed.

\section{Statistical analysis}

The chi square test or Fisher's exact was used to determine the significance of differences between covariates. Survival durations were calculated with the Kaplan-Meier method and analyzed by the log-rank test to compare cumulative survival durations among patient groups. In addition, the Cox proportional hazards model was used to compute univariate hazard ratios for the study parameters. In all of the tests, $p<0.05$ was defined as statistically significant. The SPSS software program (SPSS Japan, Tokyo, Japan) was used for the analyses. In vitro data are expressed as the mean \pm standard deviation, and significant difference was analyzed by the unpaired Student's $t$ test.

\section{Results}

\section{Effect of hypoxic conditions on the LOX expression of gastric cancer cells and the secretion of LOX}

Hypoxic conditions increased the number of polygonal or spindle-shaped cells resulting from EMT without siRNA treatment or with negative siRNA treatment in both OCUM-12 and OCUM-2MD3 cells after $24 \mathrm{~h}$ in culture compared with normoxic conditions (Fig. 1a, b). The expression of glycosylated LOX (about $58 \mathrm{kDa}$ ), which is the form of LOX before secretion [34, 42], was increased by hypoxia in both messenger RNA (mRNA) level and protein level compared with that under normoxia. Cells were transfected with siLOX\#1, siLOX\#2, or with unspecific siRNA used as a negative control. Treatment with siLOX\#1 or siLOX\#2 significantly $(p<0.001)$ downregulated LOX mRNA levels. Compared with the negative siRNA, siLOX\#1 and siLOX\#2 decreased the expression of glycosylated LOX of OCUM-2MD3 and OCUM-12 cells under hypoxia (Fig. 1c, e). Furthermore, hypoxic conditions increased the secretion of mature LOX (about $30 \mathrm{kDa}$ ) in the conditioned medium prepared from OCUM-12 and OCUM-2MD3 cells; this was decreased with treatments with siLOX\#1 and siLOX\#2 (Fig. 1f).

\section{Effect of hypoxic conditions on the EMT of gastric cancer cells}

The EMT of cancer cells induced by hypoxia was inhibited by treatment with two LOX siRNAs, whereas no change was observed by treatment with both $L O X$ siRNAs under normoxic condition (Fig. 1a, b). Hypoxia downregulated $\mathrm{CDH} 1 \mathrm{mRNA}$ expression level in both OCUM-12 cells and OCUM-2MD3 cells, whereas it upregulated VIM mRNA expression in OCUM-12 cells. $L O X$ knockdown by $L O X$ siRNAs significantly increased the $\mathrm{CDH} 1$ expression levels in both OCUM-12 cells and OCUM-2MD3 cells under hypoxia. VIM mRNA expression was significantly decreased by LOX siRNA in OCUM-2MD3 and OCUM12 cells (Fig. 1d). Similar results were found for protein levels by Western blot analysis (Fig. 1e). In hypoxia, LOX mRNA expression was significantly decreased by siHIF- $1 \alpha$ treatment in both OCUM-12 cells (50\% decreased) and OCUM-2MD3 cells (36\% decreased) cells (Fig. 2a). HIF1A knockdown also decreased the protein levels of glycosylated LOX in OCUM-12 and OCUM-2MD3 cells (Fig. 2b).

\section{Effect of $L O X$ siRNA on the migration and invasion abilities of gastric cancer cells}

Figure S1 shows a representative phase-contrast image of the wound-healing assay in hypoxia. The number of migrating OCUM-12 cells was significantly $(p<0.01)$ decreased by siLOX transfection (Fig. 3a). Figure S2 provides a representative phase-contrast image of OCUM2MD3 and OCUM-12 cells that invaded a $12-\mu \mathrm{m}$-pore membrane filter. The number of invading cancer cells was significantly increased under hypoxic conditions in OCUM-2MD3 and OCUM-12 cells in comparison with normoxic conditions. The invasion ability of OCUM2MD3 and OCUM-12 cells was decreased by siLOX in hypoxic conditions. 


\section{a OCUM-2MD3}

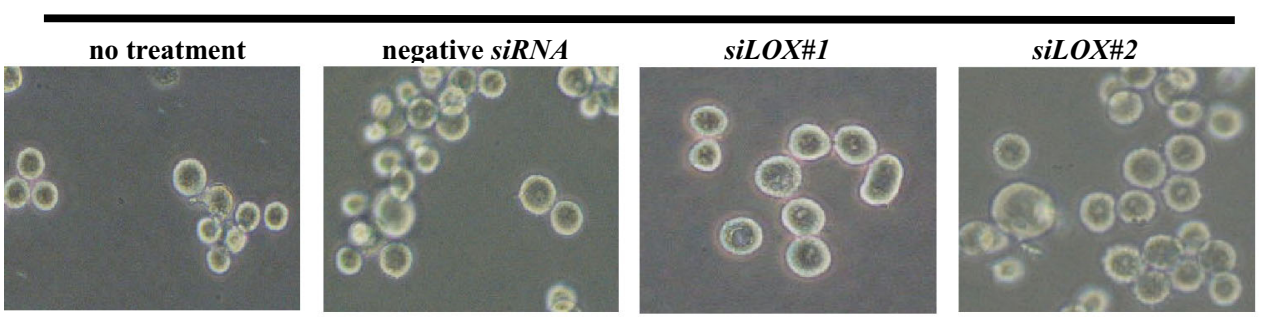

\section{Hypoxia}

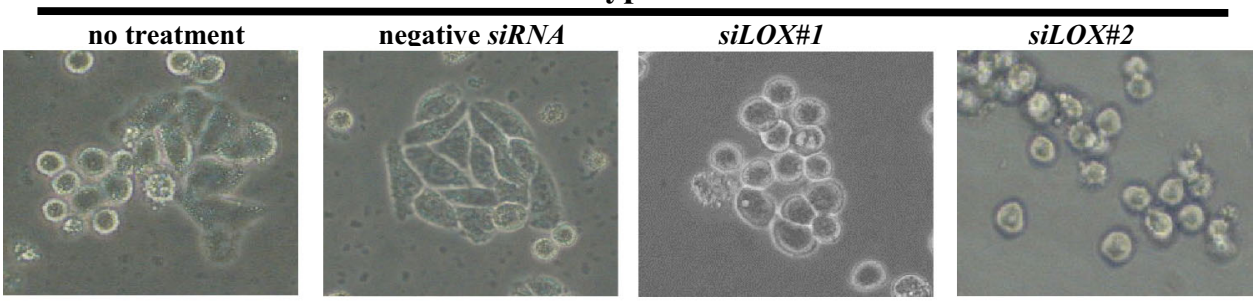

\section{b OCUM-12}

Normoxia

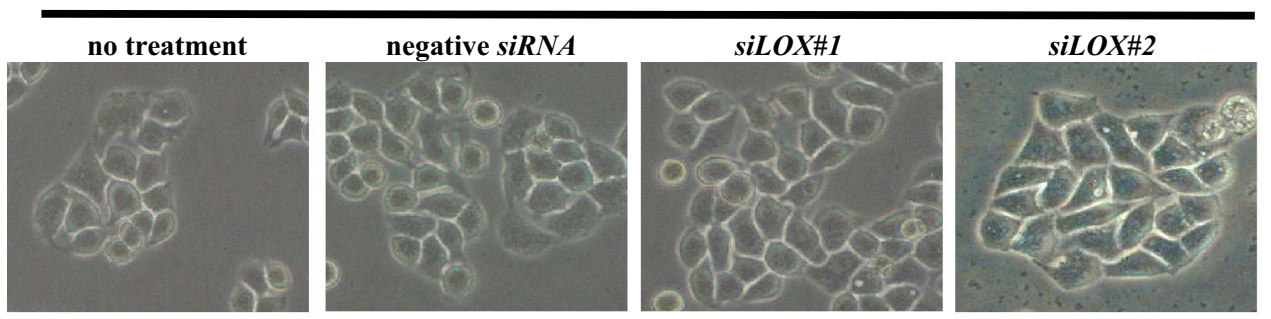

\section{Hypoxia}

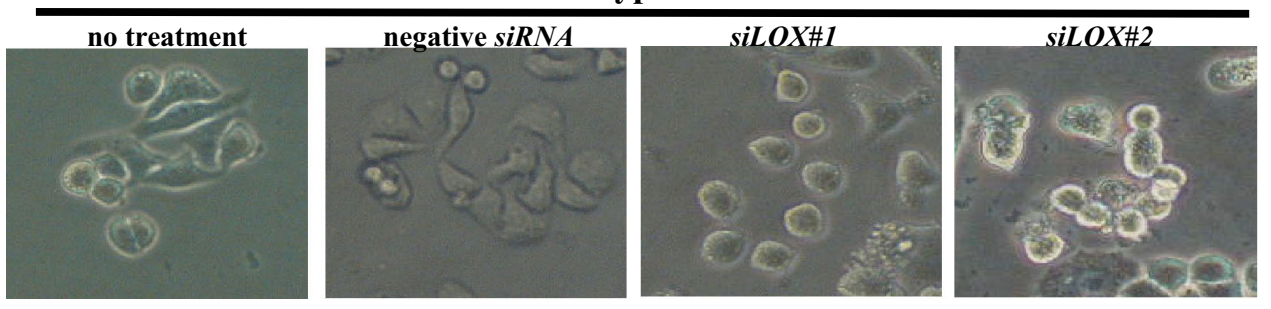

Fig. 1 Effect of LOX small interfering RNA (siRNA) knockdown on the morphology and motility of gastric cancer cells. a, b The number of polygonal or spindle-shaped cells, indicating the epithelialmesenchymal transition (EMT), was increased by hypoxic conditions in both OCUM-12 and OCUM-2MD3 cells (both without treatment and with negative siRNA treatment). The EMT under hypoxia was decreased by treatment with siLOX\#1 and siLOX\#2. c LOX expression of OCUM-12 and OCUM-2MD3 cells was effectively downregulated by siLOX\#1 and siLOX\#2. d Effects of hypoxia on the expression of E-cadherin and vimentin. E-cadherin messenger RNA $(m R N A)$ expression was significantly decreased under hypoxic conditions in OCUM-2MD3 and OCUM-12 cells. LOX knockdown inhibited the effect of hypoxia on E-cadherin expression. The expression of vimentin was significantly increased under hypoxic conditions in OCUM-12 cells, but LOX knockdown decreased vimentin expression in hypoxia. e Western blot showed increased levels of glycosylated lysyl oxidase (LOX; $58 \mathrm{kDa}$ ) in hypoxia compared with normoxia. Treatment with siLOX\#1 and siLOX\#2 decreased the expression of LOX under hypoxia. Hypoxia decreased the expression of E-cadherin and increased the expression of vimentin. LOX knockdown decreased the hypoxic effects in both OCUM-12 cells and OCUM-2MD3 cells. f The expression of mature LOX in conditioned medium prepared from OCUM-12 and OCUM2MD3 cells by Western blot. Western blot showed increased levels of mature LOX (30 kDa) in conditioned medium prepared from OCUM12 and OCUM-2MD3 cells under hypoxia. LOX knockdown decreased the level of mature LOX 
Fig. 1 continued

c OCUM-12

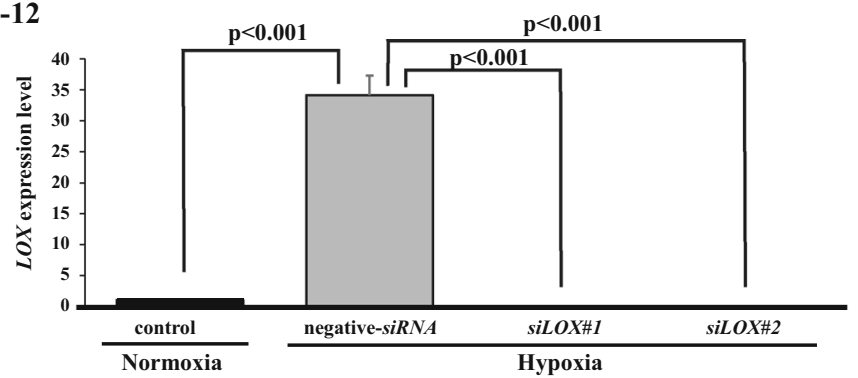

OCUM-2MD3
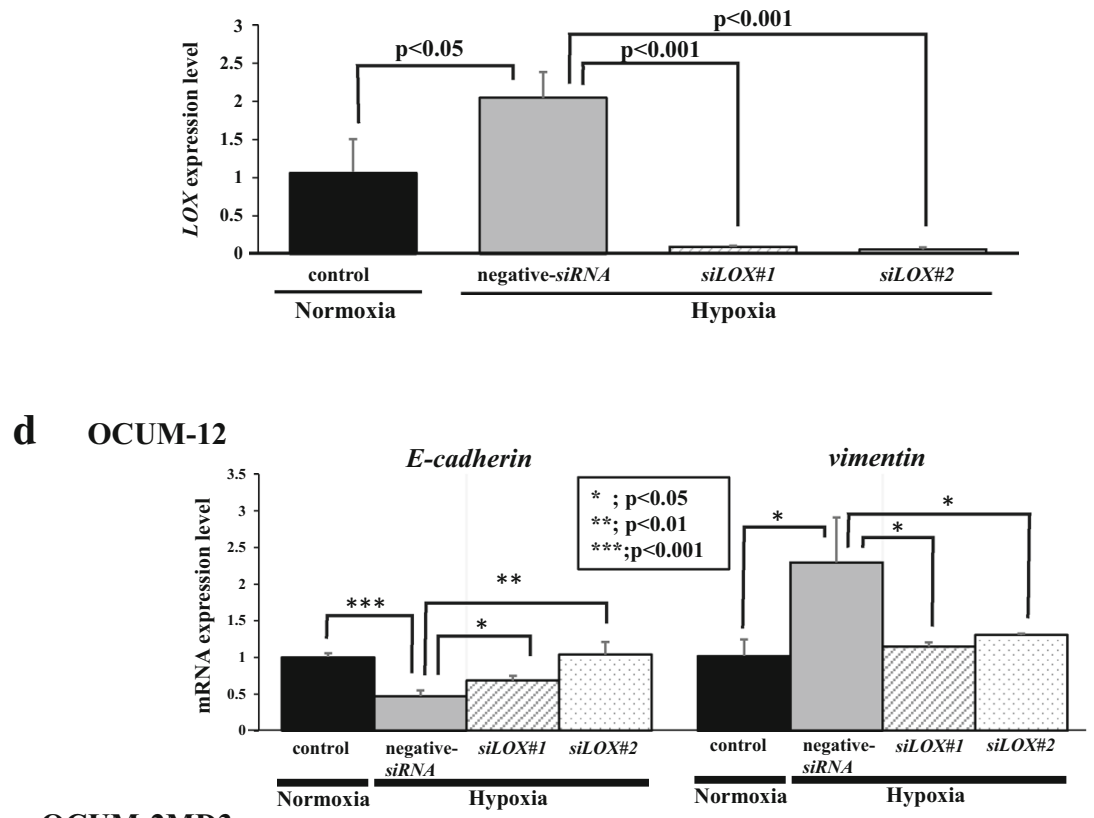

OCUM-2MD3

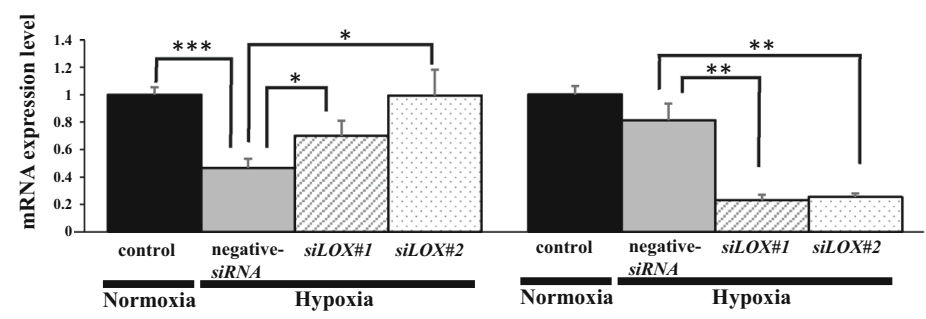

\section{Relationship between clinicopathological features and the expression of LOX in gastric cancer}

LOX expression of cancer cells was observed in the cytoplasm and nucleus, but mainly in the cytoplasm (Fig. 4a). Table 1 shows the correlation between the clinicopathological features and LOX expression in cancer cells. Among the 544 gastric cancers examined, 287 (53\%) were positive for LOX expression in cancer cells. LOX expression was correlated significantly with age, macroscopic type 4 cancers, $\mathrm{T}$ invasion (T2-T4), lymph node metastasis, intestinal-type cancers, lymphatic invasion, venous invasion, peritoneal metastasis, peritoneal cytology, and CA9 expression, but not with gender, infiltration, or hepatic metastasis. LOX expression was associated with the expression of the hypoxic marker CA9. Figure S3 shows that CA9-positive tissue exhibited heterogeneous stainability similar to that of LOXpositive tissue.

\section{Correlation between overall survival and LOX expression}

Figure $4 \mathrm{~b}$ shows that the overall survival of patients ( $n=543$ ) with LOX-positive cancer cells was significantly worse than that of patients with LOX-negative cancer cells $(p<0.001)$. Univariate analysis revealed that the overall 
Fig. 1 continued interfering RNA (siRNA) knockdown on the expression of lysyl oxidase $(L O X)$. a Effects of HIF1A knockdown on the expression of $L O X$ messenger RNA ( $m R N A$ ). LOX mRNA expression was significantly decreased by knockdown of HIFIA under hypoxic conditions in OCUM-2MD3 and OCUM-

12 cells. b Effects of HIFIA knockdown on the expression of LOX. The expression of glycosylated LOX was significantly decreased by knockdown of HIFIA under hypoxic conditions in OCUM2MD3 and OCUM-12 cells.

C.M. conditioned medium
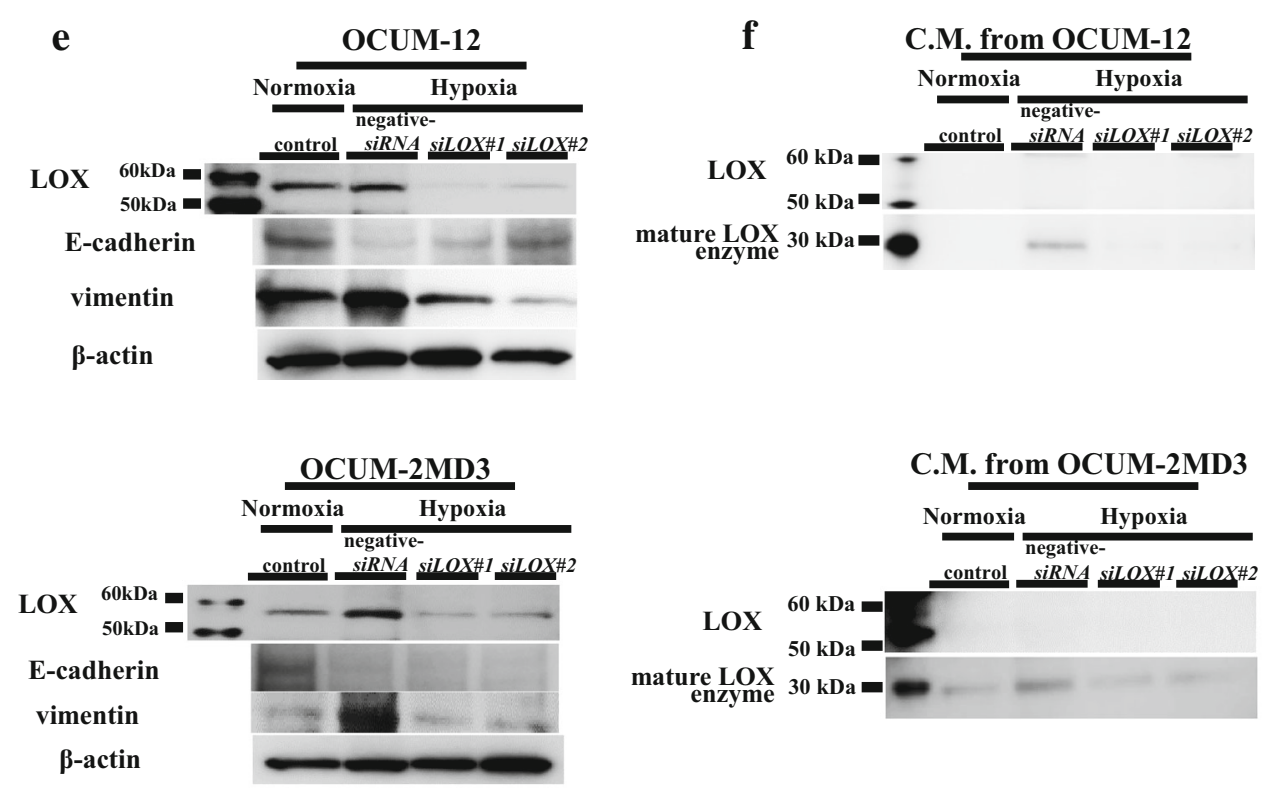

a OCUM-12
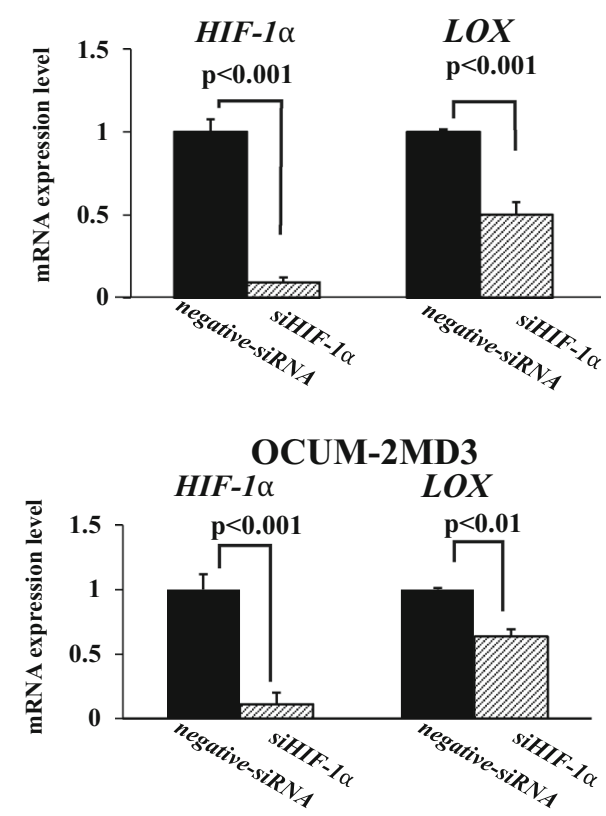

b OCUM-12
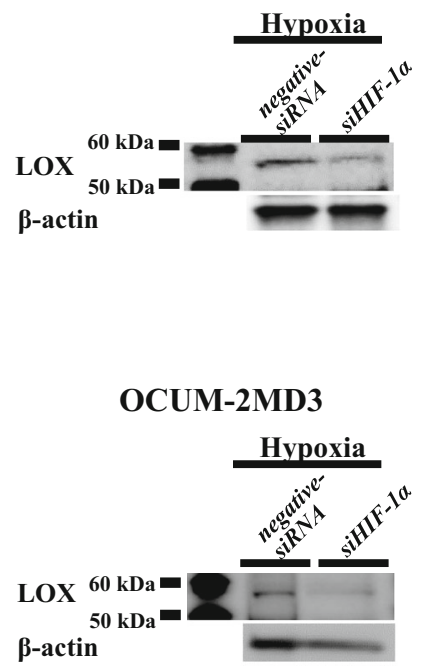

survival of patients was significantly correlated with LOX expression, macroscopic type 4 cancers, diffuse-type cancers, $\mathrm{T}$ invasion (T2-T4), lymph node metastasis, lymphatic invasion, venous invasion, infiltration, hepatic metastasis, peritoneal metastasis, and peritoneal cytology findings. Multivariable logistic regression analysis revealed that LOX expression, macroscopic type 4 cancers, $\mathrm{T}$ invasion (T2-T4), lymph node metastasis, hepatic metastasis, peritoneal metastasis, and peritoneal cytology findings were independent predictive parameters for the overall survival of patients (Table 2).

\section{Discussion}

In this study, the number of polygonal or spindle-shaped cells, indicating EMT, was increased by hypoxia in gastric cancer cells. Moreover, hypoxia decreased the level of the epithelial marker E-cadherin, and increased the level of the mesenchymal marker vimentin. Hypoxic conditions could affect the EMT of gastric cancer cells. We previously reported that hypoxia stimulated EMT of OCUM-2MD3 and OCUM-12 cells, and that TGF $\beta$ receptor (TGF $\beta R$ ) inhibitor partially suppressed the EMT of OCUM-2MD3 
Fig. 3 Effect of lysyl oxidase (LOX) on the motility of gastric cancer cells. a Effect of LOX on the migration of cancer cells under hypoxia. Treatment of OCUM-12 cells with $L O X$ small interfering RNA (siRNA) significantly inhibited the migration abilities. Data are presented as the mean and standard deviation (error bars) LOX on the invasion of cancer cells. The number of invading cells under hypoxia increased compared with the number under normoxia with treatment with the negative siRNA or without treatment. Treatment of OCUM-12 and OCUM-2MD3 cells with siLOX\#1 and siLOX\#2 significantly inhibited the invasion abilities, especially under hypoxic conditions. Data are presented as the means and standard deviation (error bars) of four experiments of four experiments. b Effect of

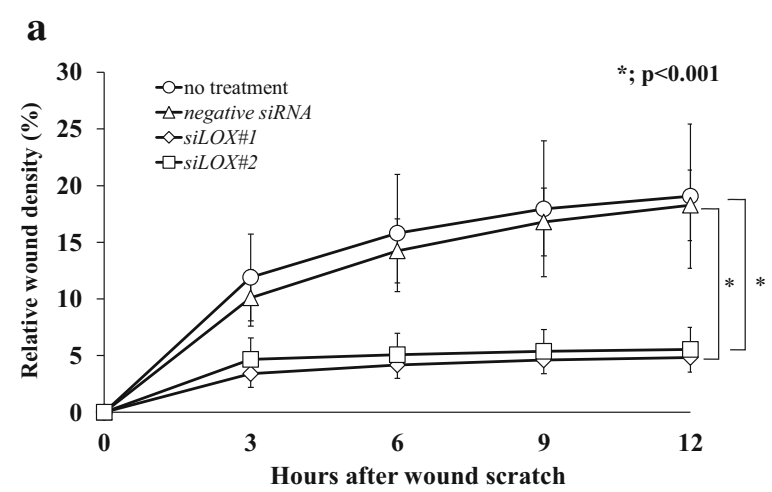

b

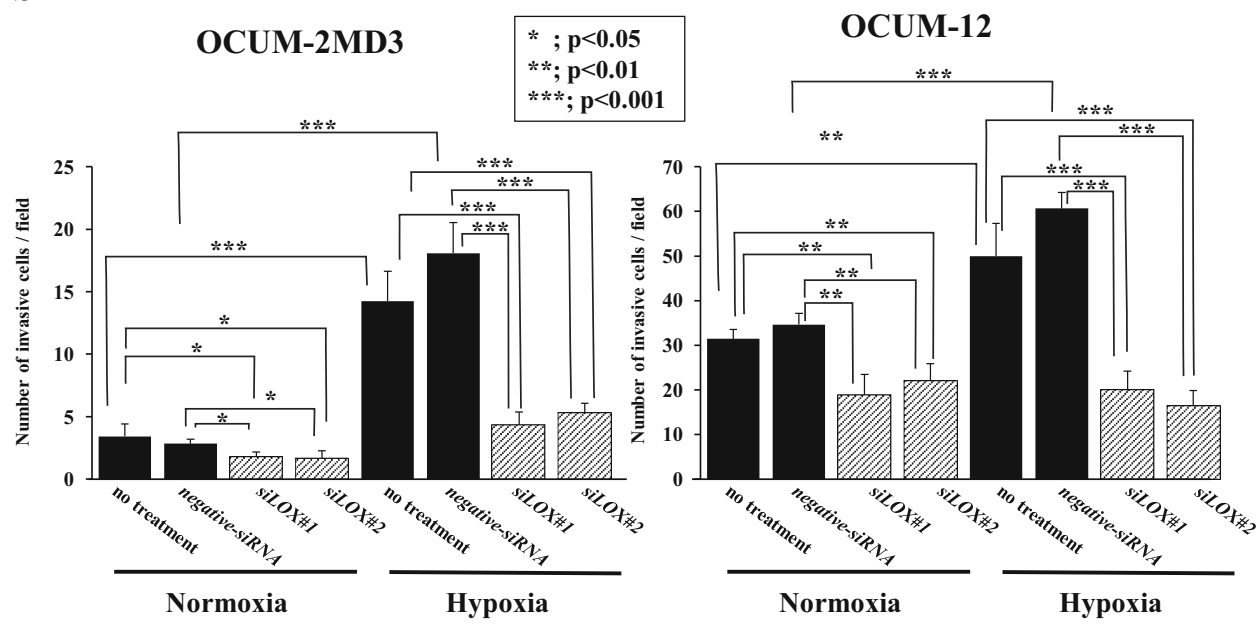

$\mathbf{a}$

Fig. 4 Expression of lysyl oxidase (LOX) and survival of patients with gastric cancer. a A representative picture of LOX staining. LOX expression was mainly found in the cytoplasm of cancer cells $(\times 400)$. b Survival of patients with gastric cancer. The overall survival of all patients ( $n=543$ ) based on LOX expression. The Kaplan-Meier survival curve indicates that the overall survival of patients with LOX expression was significantly worse than that of patients with no LOX

expression. A similar result was obtained among the patients who has undergone curative resection
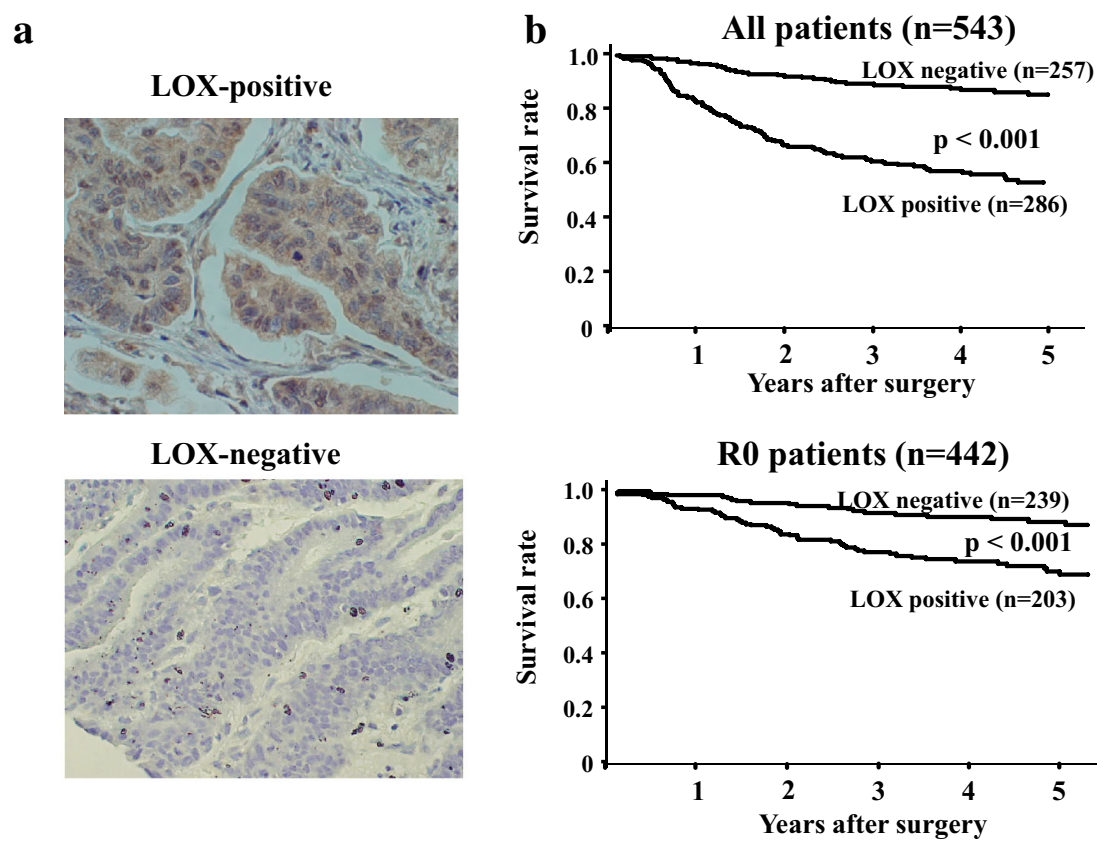
Table 1 Correlation between lysyl oxidase $(L O X)$ expression and clinicopathological features in 544 patients with gastric carcinoma

\begin{tabular}{lll}
\hline $\begin{array}{l}\text { Clinicopathological } \\
\text { features }\end{array}$ & \multicolumn{2}{c}{ LOX expression } \\
\cline { 2 - 3 } & $\begin{array}{l}\text { Positive } \\
(n=287)\end{array}$ & $\begin{array}{l}\text { Negative } \\
(n=257)\end{array}$ \\
\hline
\end{tabular}

\begin{tabular}{llrl}
\hline $\begin{array}{l}\text { Age (years) } \\
<70\end{array}$ & $161(48 \%)$ & $174(52 \%)$ & 0.006 \\
$\geq 70$ & $126(60 \%)$ & $83(40 \%)$ &
\end{tabular}

Gender

$\begin{array}{lll}\text { Female } & 116(50 \%) & 116(50 \%) \\ \text { Male } & 171(55 \%) & 141(45 \%)\end{array}$

0.298

Macroscopic type

$\begin{array}{lrrr}\text { Other type } & 242(49 \%) & 247(51 \%) & <0.001 \\ \text { Type } 4 & 45(82 \%) & 10(18 \%) & \end{array}$

$\begin{array}{llll}\text { Histological type } & & & \\ \text { Intestinal type } & 160(59 \%) & 110(41 \%) & 0.003 \\ \text { Diffuse type } & 127(46 \%) & 147(54 \%) & \end{array}$

$\mathrm{T}$ invasion

$\mathrm{T} 1$

T2-T4

$$
87(35 \%)
$$

$163(65 \%)$

$<0.001$

$200(68 \%) \quad 94(32 \%)$

Lymph node metastasis

Negative
Positive

$104(35 \%) \quad 192(65 \%) \quad<0.001$

$181(74 \%)$

$64(26 \%)$

Lymphatic invasion

Negative
Positive

Venous invasion

$\begin{array}{lrrr}\text { Negative } & 213(48 \%) & 233(52 \%) & <0.001 \\ \text { Positive } & 74(76 \%) & 24(24 \%) & \end{array}$

Infiltration

Type a, b

Type c

Hepatic metastasis

$\begin{array}{lrr}\text { Negative } & 276(52 \%) & 253(48 \%) \\ \text { Positive } & 11(73 \%) & 4(27 \%)\end{array}$

Peritoneal metastasis

$\begin{array}{lrrr}\text { Negative } & 259(51 \%) & 252(49 \%) & <0.001 \\ \text { Positive } & 28(85 \%) & 5(15 \%) & \end{array}$

Peritoneal cytology findings

\begin{tabular}{lrrr} 
Negative & $218(50 \%)$ & $217(50 \%)$ & $<0.001$ \\
Positive & $45(80 \%)$ & $11(20 \%)$ & \\
\hline
\end{tabular}

Table 1 continued

\begin{tabular}{llll}
\hline $\begin{array}{l}\text { Clinicopathological } \\
\text { features }\end{array}$ & \multicolumn{2}{l}{ LOX expression } & \\
\cline { 2 - 3 } & $\begin{array}{l}\text { Positive } \\
(n=287)\end{array}$ & $\begin{array}{l}\text { Negative } \\
(n=257)\end{array}$ & \\
\hline & & & \\
CA9 expression & $124(45 \%)$ & $153(55 \%)$ & $<0.001$ \\
Negative & $159(64 \%)$ & $89(36 \%)$ & \\
Positive & &
\end{tabular}

CA9 carbonic anhydrase 9

and OCUM-12 cells [36], which suggests that there exists another factor, besides TGF $\beta / T G F \beta R$ signaling, responsible for the EMT of cancer cells in hypoxia. In this study, we found that not only TGF $\beta$ signaling but also LOX affects the EMT of gastric cancer cells under hypoxic conditions. We focused on the role of LOX associated with the invasion ability of gastric cancer cells in this study. It has been reported that LOX families are associated with EMT signaling $[25,43,44]$. Thus, we examined the relationship between hypoxia-induced LOX and EMT in gastric cancer cells.

To investigate the role of LOX, we used two LOX siRNAs to knock down $L O X$ mRNA in RT-PCR and antiLOX antibody, which could detect the glycosylated LOX (about $58 \mathrm{kDa}$ ), the form of LOX before secretion, and mature LOX (about $30 \mathrm{kDa}$ ). We investigated the LOX knockdown in mRNA level by a primer set of LOX which is designed for sequences of LOX before secretion (proLOX) and mature LOX, not of LOX-PP. LOX knockdown inhibited the morphologic changes to polygonal or spindle shaped gastric cancer cells under hypoxia. In addition, under hypoxia, $L O X$ knockdown upregulated $C D H 1$ and downregulated VIM, which are recognized as processes involved in the mesenchymal-epithelial transition. These findings suggested that LOX is one of factors responsible for EMT of cancer cells in hypoxia. Several studies examining the relationship between LOX families and EMT previously reported that inactivation of LOX by $\beta$ aminopropionitrile, an active site inhibitor of LOX, also inhibited the hypoxia-induced EMT of cervical cancer cells [25], and LOX induced by hypoxia was correlated with the expression of EMT markers, such as Snail [45] and Twist [46]. Furthermore, LOX-like 2 interacts with and stabilizes Snail 1, promoting $\mathrm{CDH} 1$ silencing, resulting in inducement of EMT [47, 48]. Further investigations are requited to clarify the expression of EMT inducers with LOX.

LOX expression of cancer cells was observed in the cytoplasm and nucleus, but mainly in the cytoplasm. LOX enters the cells and moves into nuclei in a manner that appears to be independent of its catalytic activity, as previously reported [49]. In this study, LOX-positive gastric cancer was found to be associated with tumor cell invasion, 
Table 2 Univariate and multivariate Cox multiple regression analysis with respect to overall survival after surgery in 544 patients with gastric carcinoma

\begin{tabular}{|c|c|c|c|c|c|c|}
\hline \multirow[t]{2}{*}{ Parameter } & \multicolumn{3}{|l|}{ Univariate } & \multicolumn{3}{|l|}{ Multivariate } \\
\hline & Hazard ratio & $95 \% \mathrm{CI}$ & $p$ & Hazard ratio & $95 \% \mathrm{CI}$ & $p$ \\
\hline \multicolumn{7}{|l|}{ LOX expression } \\
\hline Positive & 4.091 & $2.749-6.089$ & $<0.001$ & 1.704 & $1.100-2.641$ & 0.017 \\
\hline \multicolumn{7}{|c|}{ Macroscopic type } \\
\hline Type 4 & 7.474 & $5.288-10.564$ & $<0.001$ & 1.954 & $1.216-3.138$ & 0.006 \\
\hline \multicolumn{7}{|c|}{ Histological type } \\
\hline Diffuse type & 1.799 & $1.305-2.479$ & $<0.001$ & 1.4254 & $0.944-2.147$ & 0.092 \\
\hline \multicolumn{7}{|l|}{$\mathrm{T}$ invasion } \\
\hline T2-T4 & 7.980 & $4.992-12.756$ & $<0.001$ & 1.998 & $1.008-3.959$ & 0.047 \\
\hline \multicolumn{7}{|c|}{ Lymph node metastasis } \\
\hline Positive & 8.377 & $5.566-12.610$ & $<0.001$ & 3.623 & $1.911-6.871$ & $<0.001$ \\
\hline \multicolumn{7}{|c|}{ Lymphatic invasion } \\
\hline Positive & 5.526 & $3.603-8.474$ & $<0.001$ & 0.990 & $0.536-1.828$ & 0.975 \\
\hline \multicolumn{7}{|c|}{ Venous invasion } \\
\hline Positive & 3.291 & $2.379-4.554$ & $<0.001$ & 1.065 & $0.724-1.567$ & 0.748 \\
\hline \multicolumn{7}{|c|}{ Infiltration type c } \\
\hline Positive & 1.817 & $1.315-2.511$ & $<0.001$ & 0.701 & $0.436-1.128$ & 0.143 \\
\hline \multicolumn{7}{|c|}{ Hepatic metastasis } \\
\hline Positive & 6.555 & $3.696-11.628$ & $<0.001$ & 3.543 & $1.870-6.713$ & $<0.001$ \\
\hline \multicolumn{7}{|c|}{ Peritoneal metastasis } \\
\hline Positive & 9.110 & $6.016-13.796$ & $<0.001$ & 2.283 & $1.360-3.834$ & 0.002 \\
\hline \multicolumn{7}{|c|}{ Peritoneal cytology findings } \\
\hline Positive & 7.440 & $5.250-10.541$ & $<0.001$ & 2.337 & $1.496-3.650$ & $<0.001$ \\
\hline
\end{tabular}

CI confidence interval, LOX lysyl oxidase

lymph node metastasis, lymphatic invasion, venous invasion, and peritoneal dissemination. LOX knockdown decreased the migration and invasion ability of cancer cells in vitro. Furthermore, we examined the expression of mature LOX in conditioned medium of gastric cancer cells, and showed that hypoxia increased the expression of mature LOX and that the influence of hypoxia was decreased by LOX knockdown, which explains that LOX is associated with invasive ability of gastric cancer cell not only by intracellular signaling but also by enzymatic activity in extracellular matrix.

Gastric carcinoma patients with LOX expression have significantly poorer prognosis than those without LOX expression. Multivariate analysis revealed that overall survival correlated significantly with LOX expression. These findings suggest that LOX plays an important role for the invasion ability of gastric cancer cells, and that LOX is a useful predictive prognostic factor in patients with gastric cancer.

Many studies have shown that increased LOX expression is associated with malignant progression of cancer cells [17, 31, 50], whereas some studies reported that $50-\mathrm{kDa}$ pro-LOX or its cleaved $18-\mathrm{kDa}$ product (LOX-PP) may have tumor-suppressive function [21-24]. One of the reasons responsible for the differences between these reports and our study might be the different the cell lines. Another reason is that Kaneda et al. showed the upregulation of proliferative activities in vitro and in vivo by inactivation of LOX through methylation and loss of heterozygosity. In this study, we focused on the role of LOX associated with the invasive abilities of gastric cancer cells under hypoxia. Hypoxia was shown to upregulate protein expression of $58-\mathrm{kDa}$ glycosylated LOX in cell lysates and $30-\mathrm{kDa}$ mature LOX in conditioned medium. Upregulation of $L O X$ increased the invasive abilities of OCUM2-MD3 and OCUM-12 cells. Knockdown of LOX diminished the hypoxic effect on EMT and invasive abilities. Tumor-suppressive activity of LOX in gastric cancer cells was unclear in this study, as we did not perform a cell proliferation assay or an in vivo assay, nor did we analyze the $18-\mathrm{kDa}$ LOX-PP, a cleaved product from pro-LOX showing tumor-suppressor activities in prostate cancer [22] and breast cancer [24]. Our findings, however, suggest that LOX before secretion and/or the 30-kDa mature LOX might be associated with EMT and invasive abilities under hypoxic conditions in gastric cancer cells. 
An immunohistochemical study indicated that LOX expression was associated with a hypoxic microenvironment evaluated by CA9, and that it is overexpressed in response to tumor hypoxia in many common tumor types [51-54]. We previously reported that the expression of CA9 might be associated with aggressive tumor phenotypes of gastric carcinomas [41]. Some studies have also demonstrated that $L O X$ is a hypoxia-responsive gene correlated with the migration and invasion of cancer cells [25, 31, 32]. Together, these findings suggest that LOX expression is associated with the high invasion activity of gastric cancer under hypoxic conditions. Furthermore, HIFIA knockdown might downregulate the expression of $L O X$. In contrast, it has been reported that $L O X$ is regulated by TGF $\beta$ signaling [55] which is upreglated in hypoxic conditions [36], which suggests that TGF $\beta$ is also associated with $L O X$ mRNA expression in hypoxic conditions.

In conclusion, LOX affects the EMT of gastric cancer cells under hypoxic conditions. LOX expression is a useful prognostic factor in patients with gastric cancer.

Acknowledgments This study was partially funded by KAKENHI (Grant-in-Aid for Scientific Research nos. 22390262, 23390329, and 26293307), by the National Cancer Center Research and Development Fund (23-A-9), and by the Priority Research Fund of Osaka City University.

Conflict of interest The authors declare that they have no conflict of interest.

\section{References}

1. Lunt SJ, Chaudary N, Hill RP. The tumor microenvironment and metastatic disease. Clin Exp Metastasis. 2009;26:19-34.

2. Hockel M, Schlenger K, Hockel S, Vaupel P. Hypoxic cervical cancers with low apoptotic index are highly aggressive. Cancer Res. 1999;59:4525-8.

3. Xing F, Okuda H, Watabe M, Kobayashi A, Pai SK, Liu W, et al. Hypoxia-induced Jagged 2 promotes breast cancer metastasis and self-renewal of cancer stem-like cells. Oncogene. 2011;30:4075-86.

4. Zhong H, De Marzo AM, Laughner E, Lim M, Hilton DA, Zagzag D, et al. Overexpression of hypoxia-inducible factor $1 \alpha$ in common human cancers and their metastases. Cancer Res. 1999;59:5830-5.

5. Hockel M, Vaupel P. Tumor hypoxia: definitions and current clinical, biologic, and molecular aspects. J Natl Cancer Inst. 2001;93:266-76.

6. Gordan JD, Simon MC. Hypoxia-inducible factors: central regulators of the tumor phenotype. Curr Opin Genet Dev. 2007;17:71-7.

7. Sahlgren C, Gustafsson MV, Jin S, Poellinger L, Lendahl U. Notch signaling mediates hypoxia-induced tumor cell migration and invasion. Proc Natl Acad Sci U S A. 2008;105:6392-7.

8. Panchenko MV, Stetler-Stevenson WG, Trubetskoy OV, Gacheru SN, Kagan HM. Metalloproteinase activity secreted by fibrogenic cells in the processing of prolysyl oxidase. Potential role of procollagen C-proteinase. J Biol Chem. 1996;271:7113-9.
9. Uzel MI, Scott IC, Babakhanlou-Chase H, Palamakumbura AH, Pappano WN, Hong HH, et al. Multiple bone morphogenetic protein 1-related mammalian metalloproteinases process pro-lysyl oxidase at the correct physiological site and control lysyl oxidase activation in mouse embryo fibroblast cultures. J Biol Chem. 2001;276:22537-43.

10. Borel A, Eichenberger D, Farjanel J, Kessler E, Gleyzal C, Hulmes DJ, et al. Lysyl oxidase-like protein from bovine aorta. Isolation and maturation to an active form by bone morphogenetic protein-1. J Biol Chem. 2001;276:48944-9.

11. Xiao Q, Ge G. Lysyl oxidase, extracellular matrix remodeling and cancer metastasis. Cancer Microenviron. 2012;5:261-73.

12. Cenizo V, Andre V, Reymermier C, Sommer P, Damour O, Perrier E. LOXL as a target to increase the elastin content in adult skin: a dill extract induces the LOXL gene expression. Exp Dermatol. 2006;15:574-81.

13. Liu X, Zhao Y, Gao J, Pawlyk B, Starcher B, Spencer JA, et al. Elastic fiber homeostasis requires lysyl oxidase-like 1 protein. Nat Genet. 2004;36:178-82.

14. Kasashima H, Yashiro M, Kinoshita H, Fukuoka T, Morisaki T, Masuda G, et al. Lysyl oxidase-like 2 (LOXL2) from stromal fibroblasts stimulates the progression of gastric cancer. Cancer Lett. 2014;354:438-46.

15. Barry-Hamilton V, Spangler R, Marshall D, McCauley S, Rodriguez HM, Oyasu M, et al. Allosteric inhibition of lysyl oxidase-like-2 impedes the development of a pathologic microenvironment. Nat Med. 2010;16:1009-17.

16. Akiri G, Sabo E, Dafni H, Vadasz Z, Kartvelishvily Y, Gan N, et al. Lysyl oxidase-related protein-1 promotes tumor fibrosis and tumor progression in vivo. Cancer Res. 2003;63:1657-66.

17. Payne SL, Fogelgren B, Hess AR, Seftor EA, Wiley EL, Fong SF, et al. Lysyl oxidase regulates breast cancer cell migration and adhesion through a hydrogen peroxide-mediated mechanism. Cancer Res. 2005;65:11429-36.

18. Peinado H, Moreno-Bueno G, Hardisson D, Perez-Gomez E, Santos V, Mendiola M, et al. Lysyl oxidase-like 2 as a new poor prognosis marker of squamous cell carcinomas. Cancer Res. 2008;68:4541-50.

19. Pickup MW, Laklai H, Acerbi I, Owens P, Gorska AE, Chytil A, et al. Stromally derived lysyl oxidase promotes metastasis of transforming growth factor- $\beta$-deficient mouse mammary carcinomas. Cancer Res. 2013;73:5336-46.

20. Zhang Q, Jin XS, Yang ZY, Wei M, Zhu XC, Wang P, et al. Upregulated expression of LOX is a novel independent prognostic marker of worse outcome in gastric cancer patients after curative surgery. Oncol Lett. 2013;5:896-902.

21. Kaneda A, Wakazono K, Tsukamoto T, Watanabe N, Yagi Y, Tatematsu M, et al. Lysyl oxidase is a tumor suppressor gene inactivated by methylation and loss of heterozygosity in human gastric cancers. Cancer Res. 2004;64:6410-5.

22. Bais MV, Ozdener GB, Sonenshein GE, Trackman PC. Effects of tumor-suppressor lysyl oxidase propeptide on prostate cancer xenograft growth and its direct interactions with DNA repair pathways. Oncogene. 2014;34:1928-37.

23. Contente S, Yeh TJ, Friedman RM. Tumor suppressive effect of lysyl oxidase proenzyme. Biochim Biophys Acta. 2009; 1793:1272-8.

24. Min C, Kirsch KH, Zhao Y, Jeay S, Palamakumbura AH, Trackman PC, et al. The tumor suppressor activity of the lysyl oxidase propeptide reverses the invasive phenotype of Her-2/neu-driven breast cancer. Cancer Res. 2007;67: 1105-12.

25. Yang X, Li S, Li W, Chen J, Xiao X, Wang Y, et al. Inactivation of lysyl oxidase by $\beta$-aminopropionitrile inhibits hypoxia-induced invasion and migration of cervical cancer cells. Oncol Rep. 2013;29:541-8. 
26. Kirschmann DA, Seftor EA, Fong SF, Nieva DR, Sullivan CM, Edwards EM, et al. A molecular role for lysyl oxidase in breast cancer invasion. Cancer Res. 2002;62:4478-83.

27. Rost T, Pyritz V, Rathcke IO, Gorogh T, Dunne AA, Werner JA. Reduction of LOX- and LOXL2-mRNA expression in head and neck squamous cell carcinomas. Anticancer Res. 2003;23:1565-73.

28. Woznick AR, Braddock AL, Dulai M, Seymour ML, Callahan RE, Welsh RJ, et al. Lysyl oxidase expression in bronchogenic carcinoma. Am J Surg. 2005;189:297-301.

29. Kaneda A, Kaminishi M, Yanagihara K, Sugimura T, Ushijima T. Identification of silencing of nine genes in human gastric cancers. Cancer Res. 2002;62:6645-50.

30. Wong CC, Gilkes DM, Zhang H, Chen J, Wei H, Chaturvedi P, et al. Hypoxia-inducible factor 1 is a master regulator of breast cancer metastatic niche formation. Proc Natl Acad Sci U S A. 2011;108:16369-74.

31. Erler JT, Bennewith KL, Nicolau M, Dornhofer N, Kong C, Le QT, et al. Lysyl oxidase is essential for hypoxia-induced metastasis. Nature. 2006;440:1222-6.

32. Ji F, Wang Y, Qiu L, Li S, Zhu J, Liang Z, et al. Hypoxia inducible factor 1alpha-mediated LOX expression correlates with migration and invasion in epithelial ovarian cancer. Int J Oncol. 2013;42:1578-88.

33. Erler JT, Weaver VM. Three-dimensional context regulation of metastasis. Clin Exp Metastasis. 2009;26:35-49.

34. Erler JT, Giaccia AJ. Lysyl oxidase mediates hypoxic control of metastasis. Cancer Res. 2006;66:10238-41.

35. Levental KR, Yu H, Kass L, Lakins JN, Egeblad M, Erler JT, et al. Matrix crosslinking forces tumor progression by enhancing integrin signaling. Cell. 2009;139:891-906.

36. Matsuoka J, Yashiro M, Doi Y, Fuyuhiro Y, Kato Y, Shinto O, et al. Hypoxia stimulates the EMT of gastric cancer cells through autocrine TGF $\beta$ signaling. PLoS One. 2013;8:e62310.

37. Noda S, Yashiro M, Nshii T, Hirakawa K. Hypoxia upregulates adhesion ability to peritoneum through a transforming growth factor-beta-dependent mechanism in diffuse-type gastric cancer cells. Eur J Cancer. 2010;46:995-1005.

38. Yashiro M, Chung YS, Nishimura S, Inoue T, Sowa M. Peritoneal metastatic model for human scirrhous gastric carcinoma in nude mice. Clin Exp Metastasis. 1996;14:43-54.

39. Kato Y, Yashiro M, Noda S, Tendo M, Kashiwagi S, Doi Y, et al. Establishment and characterization of a new hypoxia-resistant cancer cell line, OCUM-12/Hypo, derived from a scirrhous gastric carcinoma. Br J Cancer. 2010;102:898-907.

40. Yashiro M, Chung YS, Nishimura S, Inoue T, Sowa M. Establishment of two new scirrhous gastric cancer cell lines: analysis of factors associated with disseminated metastasis. Br J Cancer. 1995;72:1200-10.

41. Kato Y, Yashiro M, Noda S, Kashiwagi S, Matsuoka J, Fuyuhiro $\mathrm{Y}$, et al. Expression of a hypoxia-associated protein, carbonic anhydrase-9, correlates with malignant phenotypes of gastric carcinoma. Digestion. 2010;82:246-51.

42. Kagan HM, Li W. Lysyl oxidase: properties, specificity, and biological roles inside and outside of the cell. J Cell Biochem. 2003;88:660-72.

43. Moon HJ, Finney J, Xu L, Moore D, Welch DR, Mure M. MCF-7 cells expressing nuclear associated lysyl oxidase-like 2 (LOXL2) exhibit an epithelial-to-mesenchymal transition (EMT) phenotype and are highly invasive in vitro. J Biol Chem. 2013;288:30000-8.

44. Humtsoe JO, Koya E, Pham E, Aramoto T, Zuo J, Ishikawa T, et al. Transcriptional profiling identifies upregulated genes following induction of epithelial-mesenchymal transition in squamous carcinoma cells. Exp Cell Res. 2012;318:379-90.

45. Wei L, Song XR, Sun JJ, Wang XW, Xie L, Lv LY. Lysyl oxidase may play a critical role in hypoxia-induced NSCLC cells invasion and migration. Cancer Biother Radiopharm. 2012;27:672-7.

46. El-Haibi CP, Bell GW, Zhang J, Collmann AY, Wood D, Scherber CM, et al. Critical role for lysyl oxidase in mesenchymal stem cell-driven breast cancer malignancy. Proc Natl Acad Sci U S A. 2012;109:17460-5.

47. Peinado H, Iglesias-de Del Carmen, la Cruz M, Olmeda D, Csiszar K, Fong KS, Vega S, et al. A molecular role for lysyl oxidase-like 2 enzyme in snail regulation and tumor progression. EMBO J. 2005;24:3446-58.

48. Cuevas EP, Moreno-Bueno G, Canesin G, Santos V, Portillo F, Cano A. LOXL2 catalytically inactive mutants mediate epithelial-to-mesenchymal transition. Biol Open. 2014;3:129-37.

49. Nellaiappan K, Risitano A, Liu G, Nicklas G, Kagan HM. Fully processed lysyl oxidase catalyst translocates from the extracellular space into nuclei of aortic smooth-muscle cells. J Cell Biochem. 2000;79:576-82.

50. Cox TR, Bird D, Baker AM, Barker HE, Ho MW, Lang G, et al. LOX-mediated collagen crosslinking is responsible for fibrosisenhanced metastasis. Cancer Res. 2013;73:1721-32.

51. Chen CL, Chu JS, Su WC, Huang SC, Lee WY. Hypoxia and metabolic phenotypes during breast carcinogenesis: expression of HIF-1 $\alpha$, GLUT1, and CAIX. Virchows Arch. 2010;457:53-61.

52. Shin KH, Diaz-Gonzalez JA, Russell J, Chen Q, Burgman P, Li $\mathrm{XF}$, et al. Detecting changes in tumor hypoxia with carbonic anhydrase IX and pimonidazole. Cancer Biol Ther. 2007;6:70-5.

53. Russell J, Carlin S, Burke SA, Wen B, Yang KM, Ling CC. Immunohistochemical detection of changes in tumor hypoxia. Int J Radiat Oncol Biol Phys. 2009;73:1177-86.

54. Ivanov S, Liao SY, Ivanova A, Danilkovitch-Miagkova A, Tarasova N, Weirich G, et al. Expression of hypoxia-inducible cellsurface transmembrane carbonic anhydrases in human cancer. Am J Pathol. 2001;158:905-19.

55. Voloshenyuk TG, Landesman ES, Khoutorova E, Hart AD, Gardner JD. Induction of cardiac fibroblast lysyl oxidase by TGF$\beta 1$ requires PI3K/Akt, Smad3, and MAPK signaling. Cytokine. 2011;55:90-7. 